\title{
The effect of sex on endothelial function responses to clamped hyperglycemia in type 1 diabetes
}

\author{
Ronnie Har, Vesta Lai and David Cherney
}

\begin{abstract}
Although the female sex is associated with renal protection in non-diabetic nephropathy, men and women with type 1 diabetes mellitus (T1D) have a similar risk of developing nephropathy. As hyperglycemia is associated with exaggerated effects on blood pressure and renal hyperfiltration in women versus men with T1D, we examined the influence of clamped hyperglycemia on flow mediated vasodilatation (FMD) to determine if this parameter contributes to sex-related differences in the vascular function. After a controlled diet for seven days, blood pressure, ultrasound derived FMD and circulating renin angiotensin system mediators were measured in men $(n=30)$ and women $(n=28)$ with T1D during clamped euglycemia and hyperglycemia. Men and women were similar in pre-study dietary parameters, age, diabetes duration, body mass index, HbA1c, renal function and proteinuria. The systolic blood pressure (SBP) was higher in men during clamped euglycemia (121 $\pm 2 \mathrm{vs} .108 \pm 2 \mathrm{~mm} \mathrm{Hg}$, $P<0.0001)$ and hyperglycemia $(121 \pm 2$ vs. $111 \pm 2 \mathrm{~mm} \mathrm{Hg}, P<0.0001)$, as were the circulating levels of angiotensin II $(P<0.05)$. SBP increased in response to hyperglycemia in women but not in men. Consistently with differences in blood pressure during clamped euglycemia, FMD was higher in women than in men $(8.06 \pm 0.55$ vs. $4.15 \pm 0.52 \%, P<0.0001)$. In contrast, between-group differences in FMD during clamped hyperglycemia did not reach significance owing to a decline in FMD in women, versus men, in response to clamped hyperglycemia ( $\boldsymbol{P}=\mathbf{0 . 0 4 0}$ for between-group change in FMD). Clamped hyperglycemia suppresses FMD in women, but not in men, with uncomplicated T1D, which may contribute to the relative loss of protection against renal disease progression in women with T1D.
\end{abstract}

Hypertension Research (2014) 37, 220-224; doi:10.1038/hr.2013.136; published online 3 October 2013

Keywords: endothelial function; gender; hyperglycemia; type 1 diabetes

\section{INTRODUCTION}

In non-diabetic renal disease, the female sex is protective against the development of end-stage renal disease (ESRD), but this protection is diminished in diabetes mellitus (DM). ${ }^{1-6}$ The mechanisms responsible for this loss of protection in women with DM have not been fully elucidated. In addition to sex differences, poor glycemic control is a risk factor for the development and progression of diabetic nephropathy through hyperglycemia-mediated activation of the renin-angiotensin aldosterone system (RAS). ${ }^{7}$ Accordingly, in our previous work, we examined the differential effect of acute clamped hyperglycemia on the renal hemodynamic function and demonstrated that moderate hyperglycemia induces an exaggerated hyperfiltration response in women, compared with men. ${ }^{8}$

In addition to effects in the renal microcirculation, women exhibit differences in the macrovascular function. For example, large-vessel stiffness is increased in young women with type 1 diabetes mellitus (T1D) compared with healthy controls, a finding that was not observed in men, suggesting that DM preferentially increases arterial stiffness in women after puberty. ${ }^{9-11}$ Similar findings have been reported in patients with pre-diabetic conditions. ${ }^{12}$ To clarify the interaction between hyperglycemia and the differential effect of sex on arterial stiffness, we have measured arterial stiffness under conditions of clamped euglycemia and hyperglycemia. Surprisingly, arterial stiffness did not change in either group, despite significant increases in blood pressure in women, compared with men, suggesting that changes in arterial stiffness were not responsible for between-group differences in blood pressure.

To further elucidate the mechanisms that contribute to sexdependent differences in the vascular function, we examined the effect of clamped hyperglycemia on blood pressure and the nitric oxide (NO) system. Similar to studies involving non-DM healthy individuals among whom blood pressure is lower in women, ${ }^{13}$ we demonstrated lower blood pressures in women with uncomplicated type $1 \mathrm{DM}$, compared with a similar group of men. ${ }^{14}$ We also reported that clamped hyperglycemia induces small but significant increases in systolic blood pressure in women, compared with men, possibly because of exaggerated reductions in NO bioavailability. ${ }^{14}$ Previous work has not, however, to our knowledge determined whether sex-dependent differences in NO bioactivity modify the systemic endothelial function response to clamped hyperglycemia in patients with uncomplicated type $1 \mathrm{DM}$. The elucidation of factors responsible for the sex-equalizing effect of DM on cardiovascular and 
renal disease progression is important, since endothelial function can be modified using vasoactive drugs. ${ }^{15}$

Accordingly, we examined the effect of clamped hyperglycemia on endothelial function in patients with type $1 \mathrm{DM}$, analyzed on the basis of sex. Owing to exaggerated effects of modest clamped hyperglycemia on blood pressure and renal hyperfiltration in women, compared with men, we hypothesized that hyperglycemia would suppress brachial artery flow-mediated vasodilatation (FMD) to a greater extent in women than in men.

\section{METHODS}

\section{Participants}

Thirty men and 28 women with type $1 \mathrm{DM}$ participated in this study (Table 1). Inclusion criteria were: duration of type $1 \mathrm{DM} \geqslant 5$ years, age $\geqslant 18$ years, blood pressure $<140 / 90 \mathrm{~mm} \mathrm{Hg}$, normoalbuminuria on a 24-h urine collection, no history of renal disease or macrovascular disease or regular medications other than insulin, including oral contraceptives. Female subjects were studied during the follicular phase of the menstrual cycle, determined by cycle day and measurement of 17ß3-estradiol levels. The Research Ethics Board at the University Health Network approved the protocol, and all subjects gave informed consent.

\section{Assessment of hemodynamic parameters}

Subjects adhered to a high-sodium ( $>150 \mathrm{mmol}$ per day) and moderate-protein $(<1.5 \mathrm{~g}$ per $\mathrm{kg}$ per day) diet during the 7 -day period before each experiment, as previously described (Table 1). Euglycemic (4-6 $\left.\mathrm{mmoll}^{-1}\right)$ and hyperglycemic (9-11 $\mathrm{mmoll}^{-1}$ ) conditions were maintained on two consecutive days for $4 \mathrm{~h}$ preceding and during all investigations, a period of time demonstrated to be sufficient for the detection of changes in the vascular function. ${ }^{16}$ In all phases of the experiment, blood glucose was maintained by a modified glucose clamp technique, as previously described. ${ }^{17}$ A 16gauge peripheral venous cannula was inserted into the left antecubital vein for infusion of glucose and insulin, and a second cannula was inserted more distally for blood sampling. Blood glucose was measured every $10-15 \mathrm{~min}$, and the insulin infusion was adjusted to maintain the desired glycemic level. All experiments were performed in the same warm $\left(25^{\circ} \mathrm{C}\right)$, temperature- controlled room and in a dark, quiet environment after 10 minutes of rest in the supine position.

Following completion of the clamp, plasma angiotensin II and NO levels were obtained and glomerular filtration rate was measured using previously described inulin clearance techniques. ${ }^{18,19}$ The brachial artery endothelial function was determined by recording diameter changes of the brachial artery in response to the increased blood flow generated during reactive hyperemia (FMD). In brief, the

Table 1 Baseline clinical characteristics

\begin{tabular}{lcc}
\hline Parameter & $\begin{array}{c}\text { Men } \\
(n=30)\end{array}$ & $\begin{array}{c}\text { Women } \\
(n=28)\end{array}$ \\
\hline Age (years) & $20 \pm 1$ & $21 \pm 1$ \\
Diabetes duration (years) & $16.4 \pm 1.0$ & $15.8 \pm 1.6$ \\
Body mass index (kg m ${ }^{-2}$ ) & $24 \pm 1$ & $25 \pm 1$ \\
Glomerular filtration rate (ml min ${ }^{-1}$ per $1.73 \mathrm{~m}^{2}$ ) & $144 \pm 10$ & $133 \pm 5$ \\
Sodium excretion (mmol per day) & $218 \pm 14$ & $197 \pm 14$ \\
Protein intake (mmol per day) & $1.05 \pm 0.05$ & $0.92 \pm 0.06$ \\
Hemoglobin A1C (\%) & $8.8 \pm 0.3$ & $8.6 \pm 0.4$ \\
Estradiol in women (pmol I-1) & $\mathrm{N} / \mathrm{A}$ & $175 \pm 25$ \\
\hline
\end{tabular}

Values are means \pm s.d.; $n=$ no. of subjects. right brachial artery was scanned $2-5 \mathrm{~cm}$ above the antecubital fossa using high- resolution B-mode vascular ultrasound (Vividi, 7-15 MHz linear array transducer; GE/Vingmed, Waukesha, WI, USA). Longitudinal, electrocardiogram-gated, end-diastolic images were acquired over six cardiac cycles; the brachial arterial diameter was determined for each image using an integrated software, and the results were averaged. Diameter measurements were taken from the anterior to the posterior interface between the media and adventitia. ${ }^{20}$ After baseline images were recorded, the blood pressure cuff was inflated around the forearm, distal to the elbow, to $200 \mathrm{~mm} \mathrm{Hg}$ for 5 minutes. After cuff deflation, the increase in blood flow was measured (reactive hyperemia), along with the change in vessel diameter (endothelium-dependent dilatation), which was measured for a further 5 minutes. FMD was defined as the maximal percent changes in vessel diameter after reactive hyperemia. A single observer (DZIC.) obtained all the measurements. The intra-observer variability for repeated measurements of arterial diameters at flow-mediated vasodilatation was $0.01 \pm 0.0 .005 \mathrm{~mm}$ (absolute diameter) or $0.26 \pm 0.01 \%$ (percentage of the absolute value of the brachial artery at FMD), which is similar to that previously reported. ${ }^{20}$ Hemoglobin A1C was measured by using high-performance liquid chromatography.

\section{Statistical analysis}

The data were analyzed on the basis of gender. Results are presented as means \pm s.d. A $P$-value $\leqslant 0.05$ was considered statistically significant. On the basis of our previous work, which revealed a standard deviation of $6 \%$ in the $\triangle \mathrm{FMD}$ from baseline in response to physiological maneuvers, 24 subjects per group were required to detect a between-group difference of 5\% (80\% power, 5\% type I error). ${ }^{15,16,19}$ The sample size was therefore adequately powered to detect differences in the endothelial function. Between-group comparisons of all parameters at baseline were made using parametric methods, except in the case of NO and angiotensin II levels, which were not normally distributed and therefore analyzed using non-parametric tests. Between-group and within-group differences in all responses to hyperglycemia were determined using repeated measures analysis of variance (ANOVA), and Bonferroni's correction was used to correct for multiple comparisons. All statistical analyses were performed using the statistical package SPSS (SPSS for graduate students, Version 14.0).

\section{RESULTS}

Baseline clinical characteristics and vascular parameters during clamped euglycemia

Men and women were similar at baseline in terms of age, diabetes duration, HbAlc, body mass index, and pre-study sodium and protein intake and renal function (Table 1). The population was predominantly Caucasian - one woman was of African descent, one was of East Asian descent and one man was Hispanic. Estrogen levels in women were consistent with the late follicular phase of the menstrual cycle. Clamped glycemic conditions were successfully maintained during the studies (Figure 1). In this cohort, 13 of 30 men $(43 \%)$ and 11 of 28 women (39\%) exhibited renal hyperfiltration, defined as a GFR $\geqslant 135 \mathrm{ml} \mathrm{min} \mathrm{min}^{-1}$ per $\left.1.73 \mathrm{~m}^{2}\right){ }^{21}$

As expected from our previous work, ${ }^{22,23}$ during clamped euglycemia, systolic blood pressure and circulating angiotensin II levels were higher in men, whereas plasma NO was lower in men (Table 2, Figure 2). FMD was significantly higher in women than in men during clamped euglycemia $(8.06 \pm 0.55$ vs. $4.15 \pm 0.52 \%$, Table 2, Figure $3, P<0.0001$ ). 


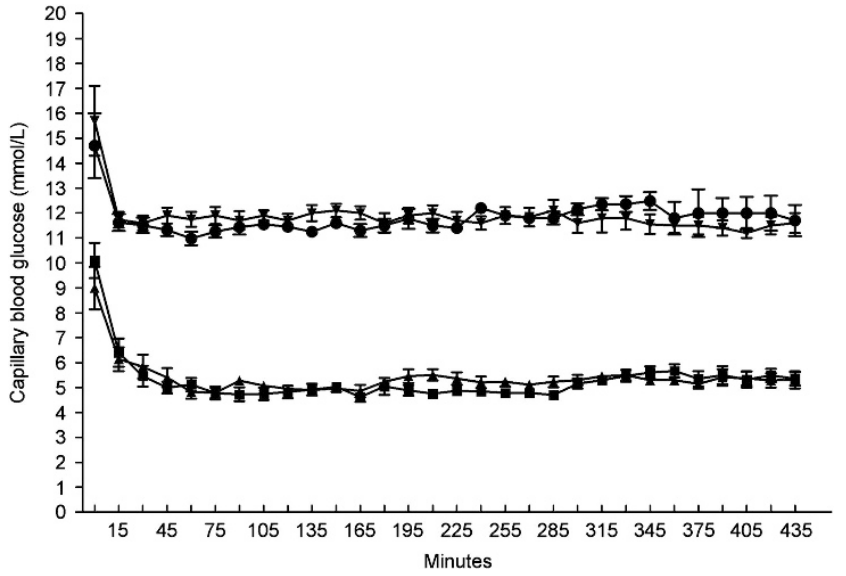

Figure 1 Glucose clamp levels in men and women with type 1 diabetes (mean \pm s.d.). $\Delta$ Men-euglycemia, - Women-euglycaemia, - Menhyperglycemia, $\boldsymbol{\nabla}$ Women-Hyperglycemia.

Table 2 Hemodynamic and neurohormal parameters in men and women with type 1 diabetes during clamped hyperglycemia (mean \pm s.d.)

\begin{tabular}{|c|c|c|}
\hline & Euglycemia & Hyperglycemia \\
\hline & \multicolumn{2}{|c|}{ Type 1 DM-Men $(n=30)$} \\
\hline \multicolumn{3}{|l|}{ Hemodynamic parameters } \\
\hline Heart rate (beats per minute) & $71 \pm 3$ & $65 \pm 2$ \\
\hline Systolic blood pressure $(\mathrm{mm} \mathrm{Hg})$ & $121 \pm 2$ & $121 \pm 2$ \\
\hline Diastolic blood pressure $(\mathrm{mm} \mathrm{Hg})$ & $68 \pm 2$ & $64 \pm 2$ \\
\hline FMD (\%) & $4.15 \pm 0.52$ & $5.22 \pm 0.40$ \\
\hline \multicolumn{3}{|l|}{ Neurohormones } \\
\hline Nitric oxide $\left(\mu \mathrm{mol} \mathrm{I}^{-1}\right)$ & $35 \pm 2$ & $35 \pm 3$ \\
\hline Angiotensin II (pmol I-1) & $3.2 \pm 0.6$ & $2.1 \pm 0.2$ \\
\hline & \multicolumn{2}{|c|}{ Type 1 DM-Women $(n=28)$} \\
\hline \multicolumn{3}{|l|}{ Hemodynamic parameters } \\
\hline Heart rate (beats per minute) & $75 \pm 3$ & $73 \pm 2$ \\
\hline Systolic blood pressure $(\mathrm{mm} \mathrm{Hg})$ & $108 \pm 2^{a}$ & $111 \pm 2^{\mathrm{a}, \mathrm{b}}$ \\
\hline Diastolic blood pressure $(\mathrm{mm} \mathrm{Hg})$ & $66 \pm 1$ & $63 \pm 1$ \\
\hline FMD (\%) & $8.06 \pm 0.55^{a}$ & $6.91 \pm 0.70^{c}$ \\
\hline \multicolumn{3}{|l|}{ Neurohormones } \\
\hline Nitric oxide $\left(\mu \mathrm{mol} \mathrm{I}^{-1}\right)$ & $48 \pm 5^{d}$ & $53 \pm 6^{d}$ \\
\hline Angiotensin II (pmol I-1) & $1.5 \pm 0.2^{d}$ & $1.3 \pm 0.1^{\mathrm{d}}$ \\
\hline
\end{tabular}

a $P<0.0001$ for SBP and FMD in men vs. women at the corresponding study time point. ${ }^{\mathrm{b}} P=0.007$ for the rise in blood pressure in women in response to clamped hyperglycemia. ${ }^{c} P=0.04$ for the change in FMD in men vs. women in response to clamped hyperglycemia. $\mathrm{d} P<0.02$ for levels of plasma nitric oxide and angiotensin II in men vs women at the corresponding study time point.

Vascular parameters and the response to clamped hyperglycemia As expected, systolic blood pressure (SBP) increased significantly in women, but not in men, in response to clamped hyperglycemia (between-group effect, $P=0.007$, Table 2, Figure 2). Circulating angiotensin II levels remained higher in men, and plasma NO remained lower in men during clamped hyperglycemia (Table 2). Even though circulating levels of NO remained higher in women during clamped hyperglycemia suggesting a state of elevated NO production, FMD declined, compared with men $(8.06 \pm 0.55$ to $6.91 \pm 0.70 \%, P=0.040$ for the change in FMD vs. men, Figure 4). Owing to this decrease in FMD in women in response to clamped hyperglycemia, between-group FMD differences were no longer significant.

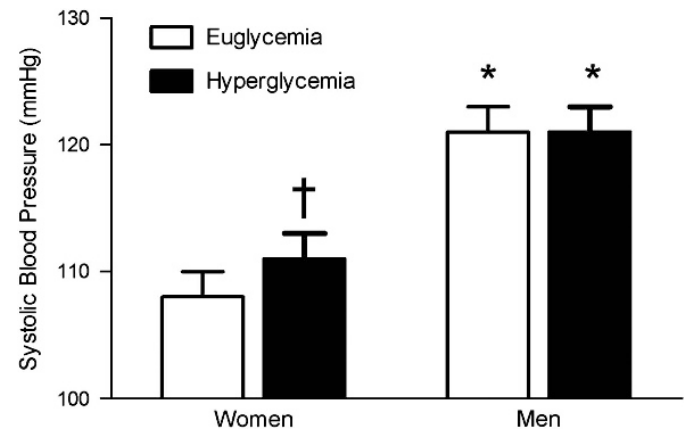

Figure 2 Systolic blood pressure (SBP) in men and women with uncomplicated type 1 diabetes (mean \pm s.d.). ${ }^{*} P<0.0001$ for difference in FMD in men compared with women.

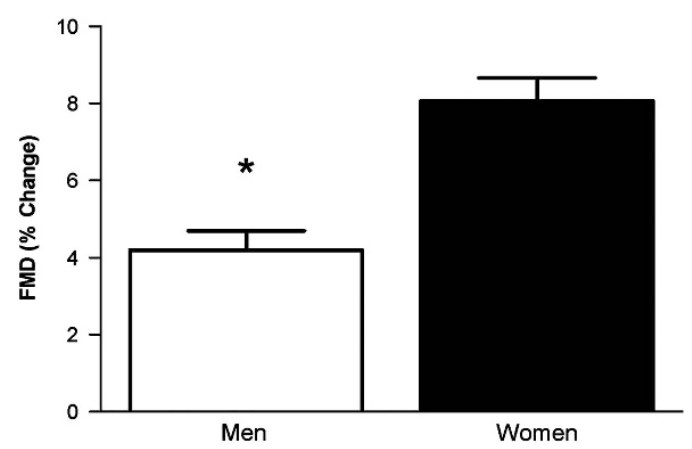

Figure 3 Flow mediated vasodilatation (FMD) in men and women with uncomplicated type 1 diabetes (mean \pm s.d.). ${ }^{*} P<0.0001$ for difference in FMD in men compared with women.

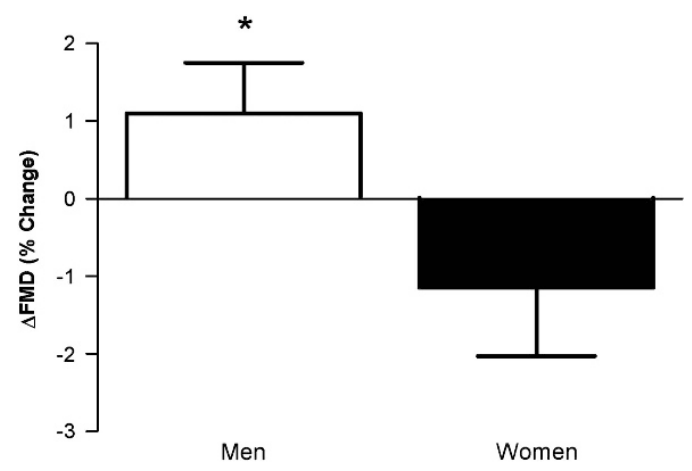

Figure 4 Change in flow mediated vasodilatation (FMD) in response to clamped hyperglycemia men and women with uncomplicated type 1 diabetes (mean \pm s.d.). ${ }^{*} P=0.04$ for between-group effect of clamped hyperglycemia on FMD in men compared to women.

\section{DISCUSSION}

Previous studies of patients with type $1 \mathrm{DM}$ have demonstrated that compared with men, women exhibit different acute blood pressure and renal hemodynamic responses to moderate clamped hyperglycemia. ${ }^{8,22}$ To clarify the role of the endothelial function in the pathogenesis of sex-dependent blood pressure differences in the response to high glucose, we measured FMD in young men and women with uncomplicated type $1 \mathrm{DM}$ during clamped euglycemia and hyperglycemia. Our first major finding was that during clamped euglycemia, blood pressure was lower and FMD was higher in women than in men. Second, these between-group sex differences were no 
longer significant under conditions of moderate clamped hyperglycemia owing to a decline in FMD in women, compared with men.

Consistently higher values for FMD in healthy pre-menopausal women compared with age-matched men may protect against renal and cardiovascular disease progression. After menopause, however, FMD declines rapidly, which may contribute to the increased risk of vascular disease in older women. ${ }^{24-26}$ Interestingly, this agedependent decline in FMD after menopause can be corrected with estrogen replacement therapy, ${ }^{27,28}$ and similar benefits have been observed with estrogen therapy in male-to-female transsexual patients. ${ }^{29}$ Furthermore, as estrogen enhances NO production in experimental models and in humans, it has been hypothesized that enhanced estrogen-mediated NO activity is responsible for greater FMD in women, as well as renal and vascular protective effects observed in non-DM women. ${ }^{30-33}$ Estrogen may also improve the vascular function through suppression of vasoconstrictors such as endothelin- $1 .{ }^{34}$

In addition to the effect of estrogen, other sex steroids can exert significant effects on the vascular function. Progesterone, for example, is natriuretic, although the resulting effects on blood pressure lowering vary based on the hormone formulation. ${ }^{35,36}$ Progesterone is also associated with vascular relaxation and facilitates similar estrogen-mediated effects, although these interactions are not consistent, as reviewed by others. ${ }^{37}$ Male sex hormones are also associated with effects on the blood pressure and vascular function, and may have contributed to our results. For example, testosterone activates the RAAS and increases salt-sensitivity, leading to elevations in blood pressure. ${ }^{38,39}$ Although testosterone can also induce endothelium dependent vasorelaxation in some studies, the increase in blood pressure seen with testosterone in most studies suggests that effects on FMD are relatively minor and do not prevent the higher blood pressures that are typical for men. ${ }^{40}$

The interaction between sex hormones and NO physiology is less well understood in the context of DM, as hyperglycemia can impair NO bioactivity. For example in streptozotocin-induced DM, induction of hyperglycemia attenuates NO synthase activity in female, compared with male animals, suggesting that the typical increase in NO bioactivity in non-DM states is blunted by the presence of DM. In patients with type $2 \mathrm{DM}$, renal NO bioactivity is also increased, possibly owing to suppressed ambient levels of reactive oxygen species. $^{32}$ More recently, in a smaller cohort of patients with uncomplicated type $1 \mathrm{DM}$, we have demonstrated a similar increase in baseline, euglycemic NO bioactivity with lower blood pressure levels. ${ }^{14}$ Similar to observations in animal studies, in response to clamped hyperglycemia, sex-based differences in blood pressure and cGMP (a metabolic product of NO production) were abolished. Moreover, administration of the NOS substrate L-arginine normalized vascular function in women.

To further elucidate the mechanisms that contribute to the lack of female protection in DM and the potential role of NO, we measured FMD under clamped euglycemic and hyperglycemic conditions. Our goal was to examine the effect of sex on endogenous NO production under these two different ambient glycemic conditions. Perhaps not surprisingly considering previous animal work, FMD was significantly higher in women during clamped euglycemia. In conjunction with these functional vascular differences, NO was significantly higher in women than in men.

In contrast, under conditions of clamped hyperglycemia, FMD declined in women, compared with the response in men. Despite declines in FMD in women, compared with men, plasma NO remained higher in women. Our results therefore suggest that hyperglycemia exerts a preferential suppression of FMD in women, compared with men, with uncomplicated type $1 \mathrm{DM}$, and that this may be owing to reduced NO bioavailability rather than a decline in NO production. Accordingly, future work should determine whether, for example, hyperglycemia is associated with an exaggerated increase in the conversion of $\mathrm{NO}$ to reactive oxygen species such as peroxynitrite, which could account for the functional decline in FMD.

Our results may have several clinical implications for patients with type 1 DM. First, several agents, including ACE inhibitors, can influence vascular remodeling and FMD ${ }^{15,41}$ Furthermore, ACE inhibitors exert greater renal hemodynamic and renal protective effects in women than in men, possibly because of synergistic interactions with estrogen. ${ }^{8,42,43}$ Whether these preferential protective effects of ACE inhibitors in women are in part related to the changes in FMD or to responses to hyperglycemia is unknown and should be investigated in future work. In addition, in light of the important physiological effect of exogenous estrogen on FMD and declines in vascular function after menopause, novel methods of improving FMD in older women should be investigated in future work. For example, in contrast with oral estrogen, topical estrogen preparations reduce blood pressure and do not activate the renin angiotensin system. ${ }^{44}$ Whether topical estrogens mediate this potentially protective phenotype through improved FMD or through changes in vascular responses to clamped hyperglycemia requires additional study.

This study has important limitations. We minimized the effect of the small sample size by utilizing homogeneous study groups and by careful pre-study dietary preparation. The effect of variations of estrogen on the hemodynamic function in female subjects was minimized by only studying those who were pre-menopausal, nonusers of oral contraceptive medications. We also decreased variability by using a study design that allowed each subject to act as his or her own control. Although the effect of age on FMD differences in women is important, our results cannot be extrapolated to post-menopausal women, in whom the vascular effects of estrogen are reduced.

In conclusion, higher FMD levels are acutely blunted by modest hyperglycemia in women with type $1 \mathrm{DM}$ compared with men. Our results suggest that the effects on FMD may contribute to sex-based blood pressure differences within the normal range in patients with uncomplicated type $1 \mathrm{DM}$. Finally, persistently higher levels of plasma NO despite FMD suppression during clamped hyperglycemia in women suggest a decline in NO bioavailability. Further work is required to clarify the role of factors such as reactive oxygen species that may contribute to the pathogenesis of sex-dependent differences in NO bioavailability.

\section{CONFLICT OF INTEREST}

The authors declare no conflict of interest.

\section{ACKNOWLEDGEMENTS}

This work was supported by operating grants from the Heart and Stroke Foundation of Canada (to DZIC). DZIC was also supported by a Kidney Foundation of Canada Scholarship and a Canadian Diabetes AssociationKRESCENT Program Joint New Investigator Award and receives operating support from the Canadian Institutes of Health Research. Ronnie Har has received salary support from an Institute of Medical Science Entrance Award, a Banting and Best Diabetes Center-University Health Network Graduate Award and a University of Toronto Open Fellowship Award. We would also like to thank Dr Paul Yip and Jenny Cheung for their invaluable assistance with the biochemical assays included in this work. Finally, we are grateful to the study participants whose time and effort is critical to the success of our research program. Funding Source: Canadian Institutes of Health Research.

Author contributions: DZIC, RH and VL researched data and wrote the manuscript. 
1 Mangili R, Deferrari G, Di Mario U, Giampietro O, Navalesi R, Nosadini R, Rigamonti G, Spezia R, Crepaldi G. Arterial hypertension and microalbuminuria in IDDM: the Italian Microalbuminuria Study. Diabetologia 1994; 37: 1015-1024.

2 Orchard TJ, Dorman JS, Maser RE, Becker DJ, Drash AL, Ellis D, LaPorte RE, Kuller LH. Prevalence of complications in IDDM by sex and duration. Pittsburgh Epidemiology of Diabetes Complications Study II. Diabetes 1990; 39: 1116-1124.

3 Jacobsen P, Rossing K, Tarnow L, Rossing P, Mallet C, Poirier O, Cambien F, Parving $\mathrm{HH}$. Progression of diabetic nephropathy in normotensive type 1 diabetic patients. Kidney Int Suppl 1999; 71: S101-S105.

4 Breyer JA, Bain RP, Evans JK, Nahman NS Jr., Lewis EJ, Cooper M, McGill J, Berl T. Predictors of the progression of renal insufficiency in patients with insulin-dependent diabetes and overt diabetic nephropathy. The Collaborative Study Group. Kidney Int 1996; 50: 1651-1658.

5 Coonrod BA, Ellis D, Becker DJ, Bunker CH, Kelsey SF, Lloyd CE, Drash AL, Kuller LH, Orchard TJ. Predictors of microalbuminuria in individuals with IDDM. Pittsburgh Epidemiology of Diabetes Complications Study. Diabetes Care 1993; 16: 1376-1383.

6 Muhlhauser I, Bender R, Bott U, Jorgens V, Grusser M, Wagener W, Overmann H Berger M. Cigarette smoking and progression of retinopathy and nephropathy in type diabetes. Diabet Med 1996; 13: 536-543.

7 Miller JA. Impact of hyperglycemia on the renin angiotensin system in early human type 1 diabetes mellitus. J Am Soc Nephrol 1999; 10: 1778-1785.

8 Cherney DZ, Sochett EB, Miller JA. Gender differences in renal responses to hyperglycemia and angiotensin-converting enzyme inhibition in diabetes. Kidney Int 2005; 68: 1722-1728.

9 Ahimastos AA, Formosa M, Dart AM, Kingwell BA. Gender differences in large artery stiffness pre- and post puberty. J Clin Endocrinol Metab 2003; 88: 5375-5380.

10 Ryden Ahlgren A, Lanne T, Wollmer P, Sonesson B, Hansen F, Sundkvist G. Increased arterial stiffness in women, but not in men, with IDDM. Diabetologia 1995; 38 1082-1089.

11 Ahlgren AR, Sundkvist G, Sandgren T, Lanne T. Female gender increases stiffness of elastic but not of muscular arteries in type I diabetic patients. Clin Physiol Funct Imaging 2002; 22: 409-415.

12 Protogerou AD, Blacher J, Aslangul E, Le Jeunne C, Lekakis J, Mavrikakis M, Safar ME. Gender influence on metabolic syndrome's effects on arterial stiffness and pressure wave reflections in treated hypertensive subjects. Atherosclerosis 2007; 193 $151-158$

13 Pechere-Bertschi A, Burnier M. Female sex hormones, salt, and blood pressure regulation. Am J Hypertens 2004; 17: 994-1001.

14 Cherney DZI, Scholey JW, Sochett EB. Sex differences in renal responses to hyperglycemia, L-arginine and L-NMMA in humans with uncomplicated type 1 diabetes mellitus. Diabetes Care 2013; 36: 1290-1296.

15 Cherney DZ, Scholey JW, Jiang S, Har R, Lai V, Sochett EB, Reich HN. The Effect of Direct Renin Inhibition Alone and in Combination With ACE Inhibition on Endothelia Function, Arterial Stiffness, and Renal Function in Type 1 Diabetes. Diabetes Care 2012; 35: 2324-2330.

16 Cherney DZ, Reich HN, Scholey JW, Lai V, Slorach C, Zinman B, Bradley TJ. Systemic hemodynamic function in humans with type 1 diabetes treated with protein kinase Cbeta inhibition and renin-angiotensin system blockade: a pilot study. Can J Physiol Pharmacol 2012; 90: 113-121.

17 Sochett EB, Cherney DZ, Curtis JR, Dekker MG, Scholey JW, Miller JA. Impact of renin angiotensin system modulation on the hyperfiltration state in type 1 diabetes. J Am Soc Nephrol 2006; 17: 1703-1709.

18 Cherney DZ, Reich HN, Miller JA, Lai V, Zinman B, Dekker MG, Bradley TJ, Scholey JW, Sochett EB. Age is a determinant of acute hemodynamic responses to hyperglycemia and angiotensin II in humans with uncomplicated type 1 diabetes mellitus. Am J Physiol Regul Integr Comp Physiol 2010; 299: R206-R214.

19 Cherney DZ, Reich HN, Jiang S, Har R, Nasrallah R, Hebert RL, Lai V, Scholey JW, Sochett EB. Hyperfiltration and the effect of nitric oxide inhibition on renal and endothelial function in humans with uncomplicated type 1 diabetes mellitus. Am J Physiol Regul Integr Comp Physiol 2012; 303: R710-R718.

20 Cherney DZ, Lai V, Scholey JW, Miller JA, Zinman B, Reich HN. Effect of direct renin inhibition on renal hemodynamic function, arterial stiffness, and endothelial function in humans with uncomplicated type 1 diabetes: a pilot study. Diabetes Care 2010; 33 361-365.
21 Sasson AN, Cherney DZ. Renal hyperfiltration related to diabetes mellitus and obesity in human disease. World J Diabetes 2012; 3: 1-6.

22 Cherney D, Montanari A. The effect of gender on arterial stiffness responses to hyperglycemia in type 1 diabetes mellitus. Clinical and Experimental Hypertension 2013 (in press).

23 Cherney DZI, Scholey JW, Sochett EB. Gender differences in renal responses to hyperglycemia, L-arginine and L-NMMA in humans with uncomplicated type 1 diabetes mellitus. Diabetes Care 2012; 36: 1290-1296.

24 Seals DR, Moreau KL, Gates PE, Eskurza I. Modulatory influences on ageing of the vasculature in healthy humans. Exp Gerontol 2006; 41: 501-507.

25 Dengel DR, Goldberg AP, Mayuga RS, Kairis GM, Weir MR. Insulin resistance, elevated glomerular filtration fraction, and renal injury. Hypertension 1996; 28: 127-132.

26 Levenson J, Pessana F, Gariepy J, Armentano R, Simon A. Gender differences in wal shear-mediated brachial artery vasoconstriction and vasodilation. J Am Coll Cardiol 2001; 38: 1668-1674.

27 Perregaux D, Chaudhuri A, Mohanty P, Bukhari L, Wilson MF, Sung BH, Dandona P. Effect of gender differences and estrogen replacement therapy on vascular reactivity. Metabolism 1999; 48: 227-232.

28 Kawano H, Motoyama T, Kugiyama K, Hirashima O, Ohgushi M, Fujii H, Ogawa H, Yasue $\mathrm{H}$. Gender difference in improvement of endothelium-dependent vasodilation after estrogen supplementation. J Am Coll Cardiol 1997; 30: 914-919.

29 New G, Timmins KL, Duffy SJ, Tran BT, O'Brien RC, Harper RW, Meredith IT. Long-term estrogen therapy improves vascular function in male to female transsexuals. J Am Coll Cardiol 1997: 29: 1437-1444.

30 Darkow DJ, Lu L, White RE. Estrogen relaxation of coronary artery smooth muscle is mediated by nitric oxide and cGMP. Am J Physiol 1997; 272: H2765-H2773.

31 Dietz NM. Gender and nitric oxide-mediated vasodilation in humans. Lupus 1999; 8 : 402-408.

32 Schneider MP, Ritt M, Raff U, Ott C, Schmieder RE. Gender is related to alterations of renal endothelial function in type 2 diabetes. Nephrol Dial Transplant 2009; 24 3354-3359.

33 Mendelsohn ME, Karas RH. The protective effects of estrogen on the cardiovascular system. N Engl J Med 1999; 340: 1801-1811.

34 Akishita M, Kozaki K, Eto M, Yoshizumi M, Ishikawa M, Toba K, Orimo H, Ouchi Y. Estrogen attenuates endothelin-1 production by bovine endothelial cells via estrogen receptor. Biochem Biophys Res Commun 1998; 251: 17-21.

35 Seely EW, Walsh BW, Gerhard MD, Williams GH. Estradiol with or without progesterone and ambulatory blood pressure in postmenopausal women. Hypertension 1999; 33: 1190-1194.

36 Oelkers WK. Effects of estrogens and progestogens on the renin-aldosterone system and blood pressure. Steroids 1996; 61: 166-171.

37 Orshal JM, Khalil RA. Gender, sex hormones, and vascular tone. Am J Physiol Regul Integr Comp Physiol 2004; 286: R233-R249.

38 Reckelhoff JF, Zhang H, Granger JP. Testosterone exacerbates hypertension and reduces pressure-natriuresis in male spontaneously hypertensive rats. Hypertension 1998; 31: 435-439.

39 Reckelhoff JF. Gender differences in the regulation of blood pressure. Hypertension 2001; 37: 1199-1208.

40 Costarella CE, Stallone JN, Rutecki GW, Whittier FC. Testosterone causes direct relaxation of rat thoracic aorta. J Pharmacol Exp Ther 1996; 277: 34-39.

41 Arcaro G, Zenere BM, Saggiani F, Zenti MG, Monauni T, Lechi A, Muggeo M, Bonadonna RC. ACE inhibitors improve endothelial function in type 1 diabetic patients with normal arterial pressure and microalbuminuria. Diabetes Care 1999; 22 1536-1542.

42 Liu HW, Iwai M, Takeda-Matsubara Y, Wu L, Li JM, Okumura M, Cui TX, Horiuchi M. Effect of estrogen and AT1 receptor blocker on neointima formation. Hypertension 2002; 40: 451-457.

43 Ruggenenti P, Perna A, Zoccali C, Gherardi G, Benini R, Testa A, Remuzzi G. Chronic proteinuric nephropathies. II. Outcomes and response to treatment in a prospective cohort of 352 patients: differences between women and men in relation to the ACE gene polymorphism. Gruppo Italiano di Studi Epidemologici in Nefrologia (Gisen). J Am Soc Nephrol 2000; 11: 88-96.

44 Ichikawa J, Sumino H, Ichikawa S, Ozaki M. Different effects of transdermal and oral hormone replacement therapy on the renin-angiotensin system, plasma bradykinin level, and blood pressure of normotensive postmenopausal women. Am J Hypertens 2006; 19: 744-749. 